\title{
PARECERISTAS AD HOC 2020
}

O Comitê Editorial dos Cadernos CEDES agradece a colaboração dos pareceristas Ad hoc elencados a seguir, que emitiram pareceres e promoveram, com sua experiência e seu profissionalismo, a avaliação dos números temáticos publicados por este periódico no ano de 2020.

- Felipe de Souza Tarábola Universidade de São Paulo - Faculdade de Educação São Paulo (SP), Brasil

- Juliana Thimóteo Nazareno Mendes Universidade Federal Fluminense - Departamento de Serviço Social de Campos Campos dos Goytacazes (RJ), Brasil

- Marcus Aurélio Taborda de Oliveira Universidade Federal de Minas Gerais - Faculdade de Educação Belo Horizonte (MG), Brasil

- Marilda Gonçalves Dias Facci

Universidade Estadual de Maringá, Centro de Ciências Humanas Letras e Artes Maringá (PR), Brasil

- Marília Spósito Universidade de São Paulo - Faculdade de Educação São Paulo (SP), Brasil

- Marta Kohl de Oliveira Universidade de São Paulo- Faculdade de Educação São Paulo (SP), Brasil

- Vera Tereza Valdemarin Universidade Estadual Paulista - Faculdade de Ciências e Letras Araraquara (SP), Brasil 